\title{
Exploration and Analysis of Column Setup Principles for Journals of Applied Colleges and Universities
}

\author{
Wei Chengyan \\ Guangzhou College of Technology and Business, Guangzhou, Guangdong, 510850, China
}

Keywords: Applied Universities; Journals; Column Setup

\begin{abstract}
Column setup counts in construction of a university journal. A journal with scientific and reasonable column setup can better play the part of a teaching and scientific research service provider and build campus quality and image. And journals of applied colleges and universities should follow principles of application, industry, region, academics, feature and long-term sustainability, highlight its own characteristics and improve its quality.
\end{abstract}

\section{Introduction}

Column setup plays a crucial role in building a university journal. A journal can better fulfill the function of serving teaching and scientific research and establish campus quality and image if scientifically and reasonably setting up its columns. And whether a journal has excellent and featured columns is an essential condition for its sustainable development, based on which, the journal can stand out and take a place among numerous academic journals nationwide. So how to scientifically and reasonably set up columns in a journal? What makes journals of applied universities emerging in the context of education reforms different from those of famous and general universities? Applied universities are inferior to long-standing top universities such as Peking University and Tsinghua University in terms of academic research among others, hence journals of applied universities are no match for journals of such long-standing top universities in respect to the number of articles published and quality of the articles published. In order to make better development, journals of applied universities must comply with some column setup principles.

\section{Principle of Application}

Journals of applied universities mainly show educational and teaching results on campus, thus such journals should combine characteristics of their own universities, follow the principle of "application", organize and publish groundbreaking articles in experiment \& training, technical innovation and practical research among others with a purpose while soliciting contributions and setting up columns. As a result, such journals can highlight their own school running characteristics and become distinctive. Journal of Beijing Union University, for instance, combines characteristics of its own university to set such columns as "Applied Technology and Science" and "Experimental Technology and Science" considered to be better than those in peer journals and play a vital part in promoting the standard of the journal as a whole.

\section{Principle of Industry}

Applied universities generally adopt the model of management on teachers of teaching qualification and occupational qualification and require full-time teachers to spend some time doing on-the-job practice in enterprises every year. As a result, such teachers can serve as both teachers and engineers to acquaint themselves with teaching business and skills and operating skills while establishing a certain connection with enterprises in the industry and undertaking research and development work in some engineering projects in most cases. In the practice, such teachers can combine theory with practice and summarize practical and teaching experience to have a good 
knowledge of research \& development techniques, management models, marketing patterns and so on in enterprises to facilitate producing realistic, creative, practical and readable articles. It is an advantage of applied universities and their journals, which should be highlighted and turned to a distinctive feature. Besides, applied universities may hire skilled workers from enterprises in the industry to assume part-time teachers to show their own school running characteristics. Such skilled workers should be encouraged and guided with effort to write articles for journals of applied universities to make the journals more specialized and industry-oriented.

\section{Principle of Region}

Universities may launch some disciplines with local characteristics as the case may be, hence their disciplinary research findings show local characteristics, granting opportunities and chances for setting featured columns in their journals. Specifically speaking, as far as column setup is concerned, university journals should make full use of cultural characteristics and strengths where universities are situated as the case may be to reveal distinctive features of their own regional culture. Some featured columns accommodating regional development should be planned and launched intentionally to boost teaching and scientific research work on campus and guide the faculty and students to render services to regional economic construction and social life with a purpose. In turn, outstanding featured local columns can promote journal development and quality. Many journals have made an attempt with courage in highlighting their local characteristics, "Research on Qilu Culture" of Qilu Journal, "Research on Hunan Culture" of Journal of Hunan Normal University and "Hakkaology Research" of Journal of Jiaying University, to name a few.

\section{Principle of Academics}

A university oriented in an "applied university" makes a movement in all respects including its talent training objectives and models and makes better academic performance. "A university journal sponsored by a university refers to an academic theory journal mainly used for presenting the university's scientific research and teaching achievements, considered to be a crucial field for carrying out national and international academic exchange." [2] Thus, a university journal is supposed to give clarity to its orientation and attach greater importance to academics with regard to column setup.

\subsection{The set columns should cover all the major disciplines and majors in a university.}

How a university sets its disciplines and majors represents its academic nature best. And its journal as the "window" of presentation of teaching and scientific research achievements should base its column setup on its discipline setup, cover all the major disciplines and majors launched on campus and demonstrate teaching and scientific research achievements of such disciplines and majors to create a good display platform for its faculty and staff and improve their initiative to take part in teaching and scientific research activities. As long as the faculty promote the initiative of working on scientific studies, they will make more better contributions to the journal which will be better run as a matter of course.

\subsection{Key columns should highlight a university's disciplinary strengths.}

"A journal of no characteristic or feature will find it hard to survive, let alone to develop," [3] said Zou Taofen, a publisher. Sun Li also indicated that a journal should "be characteristic and brave to create a school and compete with its peer journals." [4] University journals barely stand out among a mass of specialized academic journals due to their specific journal running objectives and orientations and journals of applied universities, in particular, find it harder to take the lead among numerous journals. Therefore, as far as the column setup is concerned, journals of applied universities have no choice but present and highlight advantages, hide disadvantages and run with characteristics provided that they cover all the major disciplines and majors on campus. A university's disciplinary strengths are generally considered to be its scientific research strengths, 
based on which, it should set up columns in its journal. As a result, the journal will keep viscosity of a very limited number of contributors and readers. In fact, each university has its own disciplinary and specialty strengths, on the ground of which, it should set up featured columns in its journal.

\section{Principle of Feature}

Feature refers to the unique color and style of something and "featured column" refers to a column that makes a journal distinctive from other journals in respect of style, orientation and content presented, among which, a priority is given to orientation and content. Orientation mainly comprises purpose of column running, specialty orientation, target readers, topic design and orientation of study and so on. And content is merely concerned with specialized and academic characteristics. A journal is considered to be "academic and technical", which makes applied universities different from higher vocational colleges. And whether a journal is more "academic" or more "technical" depends on a university's orientation. From where applied universities are standing, their journals are advised to set their own characteristic columns under the guide of the university orientation.

\section{Principle of Long-term Sustainable Development}

Subject to the mechanism on how "influence" is made, influence is not made outright. Instead, only by sustainable contact can influence become valuable as time goes on. Similarly, a journal's columns will make a difference with long-standing unremitting efforts rather than one or several issues published. Thus, in order to draw attention of more contributors and readers, a journal should be focused on the continuity and stability of the column setup. Because continuous and stable columns can keep emphasizing and reinforcing the stimulus. It will be hard for a journal to make an influence if publishing twenty or thirty articles per issue in a dozen of not continuous columns which are set up for articles and frequently altered. Besides, some columns in a journal publish few articles in a year, indicating such columns are insignificant. Therefore, if a journal intends to develop and make a difference in its columns, its columns must have an "inexhaustible" range of topics covered, available for long-term development, which is considered to be an important condition for the journal's permanent development and setup of "featured" columns.

In conclusion, a journal's column setup is a vital means for the journal's sustainable development. And journals of applied universities are advised to highlight and consider the column setup to be a scientific research task to be carefully studied, elaborately designed and scientific arranged to turn columns to the journal's development highlights to stand out among numerous journals.

\section{Acknowledgement}

2017 Campus Program of Guangzhou College of Technology and Business (KA201707); 2016 Scientific Research Program of Guangdong University Journal Research Council (20160205).

\section{References}

[1] Yang Jicheng. Discussion on the Interaction between a University's Journal and Its Teaching and Scientific Research Work [J]. Journal of Hebei Energy Institute of Vocation and Technology, 2003(3): 42-44.

[2] Shao Yanyan. Psychoanalysis of Contributing Authors and Relative Strategies of Journal Editors [J]. Journal of Anshan Normal University, 2011(04): 108-110.

[3] Zang Lijuan. Review and Reflection on Development of China's University Journals Since Economic Reform [J]. Journal of Nanjing University of Science and Technology (Social Sciences), 2009(4): 111-114. 